\title{
Thrombocytopenia Induced by Giant Atrial Thrombus in Rheumatic Valve Disease- A Case Report
}

\author{
Md. Lokman Hossain ${ }^{1}$, Mahbubor Rahman ${ }^{2}$, Sadeka Dina ${ }^{3}$, Mahbubul Islam ${ }^{4}$, Md. Abdul Karim \\ Amran Ahmed ${ }^{1}$, Shameem Ahsan ${ }^{1}$ \\ ${ }^{1}$ Department of Cardiac Surgery, Labaid Cardiac Hospital, Dhaka, ${ }^{2}$ Department of Cardiology, \\ Labaid Cardiac Hospital, Dhaka, ${ }^{3}$ Department of Radiology \& Imaging, NICVD, Dhaka, ${ }^{4}$ Department \\ of Cardiac Anaesthesiology, Labaid Cardiac Hospital, Dhaka,
}

\begin{abstract}
Keywords:
Platelet, DIC, Rheumatic heart disease, Mitral stenosis, Left Atrial thrombus.

\section{Introduction:}

Mitral stenosis increases blood stasis, representing a major risk factor for left atrial clot formation. ${ }^{1,2}$ Severe thrombocytopenia, in the absence of heparin treatment or major hepatic dysfunction, could be explained by 'acute thrombosis-associated thrombocytopenia'. ${ }^{3}$ Hypothesis suggested that large fresh clots consume platelets on their surface, likely due to the exudation of thromboplastic substances. This process can be regarded as a form of disseminated intravascular coagulation. ${ }^{4,5}$ Here we report a rare case of thrombocytopenia induced by giant atrial thrombus in rheumatic valve disease with successful mitral valve replacement and removal of giant thrombus.
\end{abstract}

\begin{abstract}
:
We report a 52-year-old and weight of $79.36 \mathrm{lbs}$ female patient with Thrombocytopenia induced by giant atrial thrombus in rheumatic mitral stenosis. The patient underwent bioprosthetic mitral valve implantation and removal of the giant thrombus. The platelet count progressively increased achieving normal levels one week after surgery.
\end{abstract}

(Cardiovasc. j. 2020; 13(1): 95-96)

\section{Case Report:}

A 52-year-old and weight of $79.36 \mathrm{lbs}$ woman with no previous medical history presented with signs of congestion and rapid atrial fibrillation (Fig.-2: ECG). There was evidence of thrombocytopenia $(70 \times 10 \mathrm{E} 9 / \mathrm{L})$ and moderate elevation of transaminases, NT Pro BNP $4811 \mathrm{pg} / \mathrm{ml}$ and
Dengue NS1Ag (ICT): Negative. An abdominal ultrasonography showed no liver alterations and no splenomegaly. Transthoracic echocardiogram confirmed the findings and showed rheumatic severe mitral valve stenosis, severe TR (PASP:96

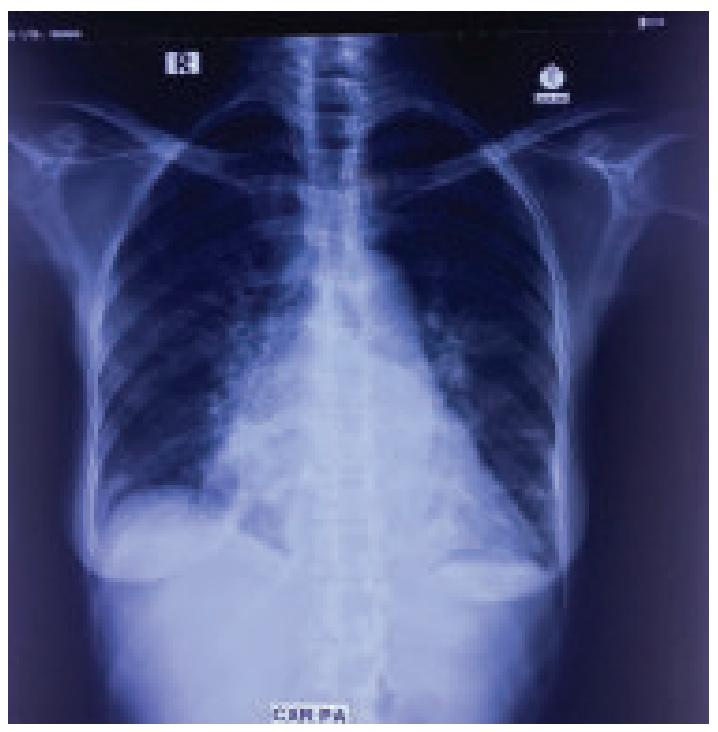

Fig.-1: $X$ - Ray of chest (PA view).

Address of Correspondence: Dr. Md. Lokman Hossain, Department of Cardiac Surgery, Labaid Cardiac Hospital, Dhanmondi, Dhaka, Bangladesh. Email : lokmancts@gmail.com,

- 2020 authors; licensed and published by International Society of Cardiovascular Ultrasound, Bangladesh Chapter and Bangladesh Society of Geriatric Cardiology. This is an Open Access article distributed under the terms of the CC BY NC 4.0 (https://creativecommons.org/licenses/by-nc/4.0) 
$\mathrm{mmHg}$ ) with severe pulmonary hypertension and a giant left atrial thrombus with pulmonary vein infiltration (Fig.3). Coronary angiography revealed normal epicardial coronary arteries. Patient underwent bioprosthetic mitral valve implantation, removal of giant thrombus (Fig. 4) and postoperative course was uneventful.

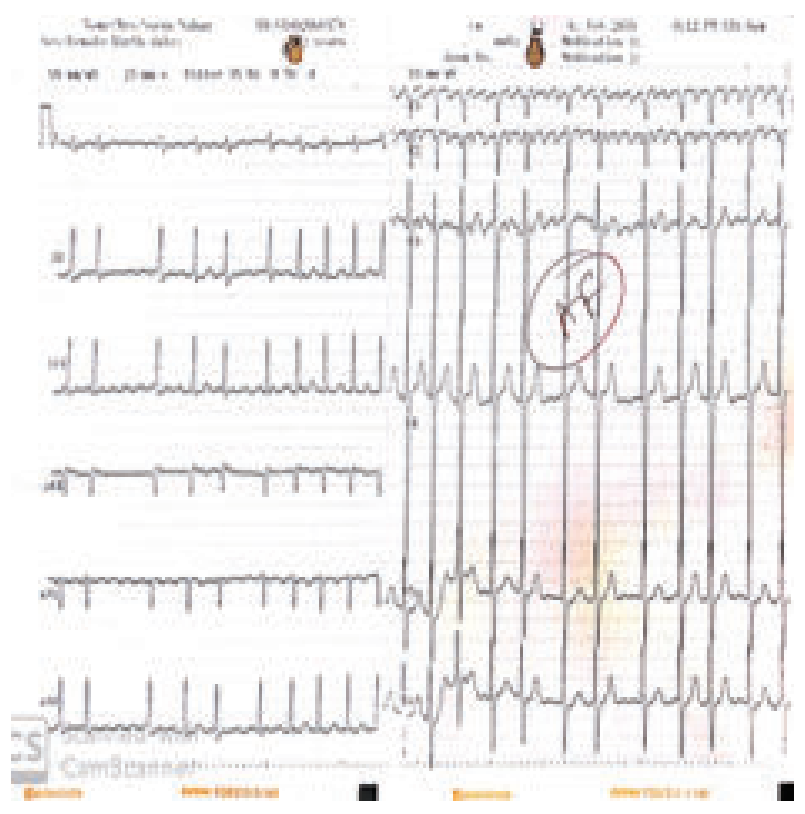

Fig.-2: ECG showing atrial fibrillation,

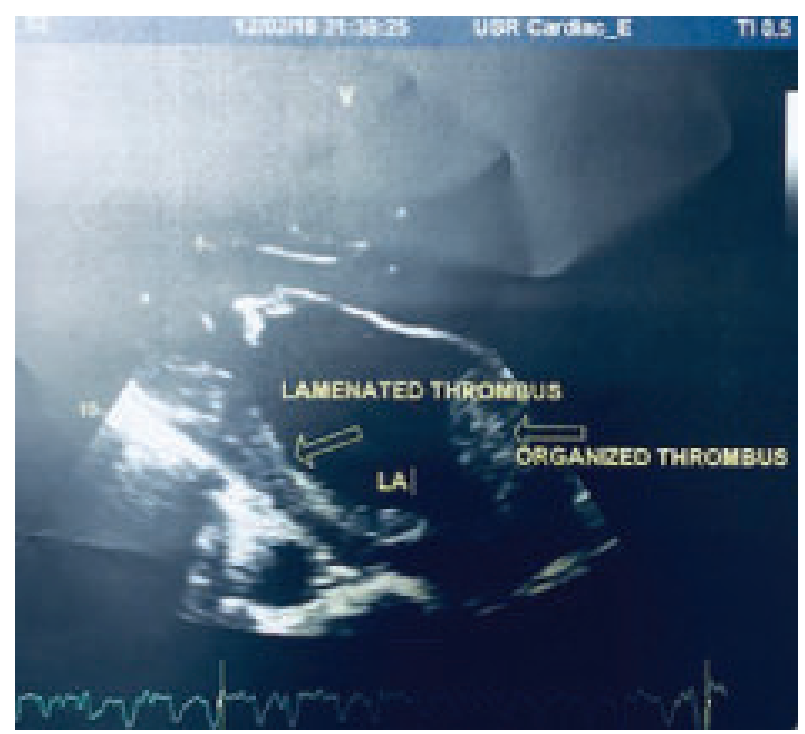

Fig.-3: Echo Laminated Organized Thrombus

The patient was discharged on the $7^{\text {th }}$ postoperative day (POD) in a very good physical condition. At $5^{\text {th }}$ POD the platelet count increased to $125 \times 10^{9} / \mathrm{L}$.

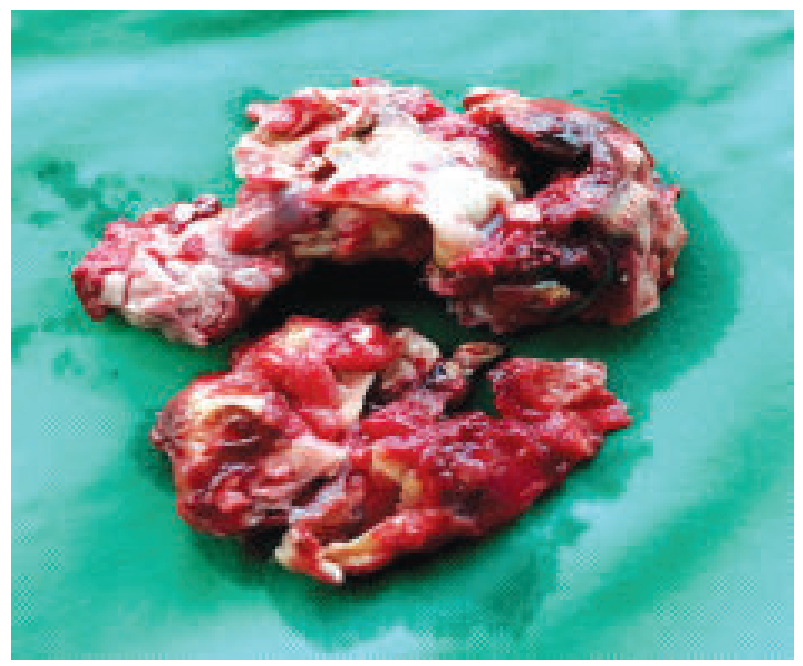

Fig.-4: Specimen LA thrombus.

She was then checked at the follow up clinic 3 weeks after the surgical intervention the platelet count became $390 \times 10^{9} / \mathrm{L}$ that drastically raised from the initial count $70 \times 10^{9} / \mathrm{L}$.

\section{Conclusion:}

A patient of severe mitral stenosis with giant left atrial thrombus causing thrombocytopenia, in whom platelet count normalized after surgical removal of the thrombus along with valve replacement.

\section{Conflict of Interest - None.}

\section{References:}

1. Chandrashekhar Y, Westaby S, Narula J. Mitral stenosis. Lancet 2009;374(9697):1271-1283. doi: 10.1016/ S0140-6736(09)60994-6.

2. Beppu S, Park YD, Sakakibara H, Nagata S, Nimura Y. Clinical features of intracardiac thrombosis based on echocardiographic observation. Jpn Circ J 1984;48(1):75-82. doi: 10.1253/jcj.48.75.

3. Kitchens CS. Thrombocytopenia due to acute venous thromboembolism and its role in expanding the differential diagnosis of heparin-induced thrombocytopenia. Am J Hematol 2004; 76: 69-73. doi: 10.1002/ajh.20009.

4. Hanano M, Takahashi H, Arakawa K, et al. Consumption coagulopathy associated with left atrial thrombosis. Hematol Pathol 1991;5(1):27-31.

5. Shao Q, Tian R, Zhang X, et al. Chronic disseminated intravascular coagulation induced by left atrial thrombus in a patient with giant "normal" heart. Medicine (Baltimore) 2016;95(51): e5501. doi: 10.1097/ MD.0000000000005501. 